\title{
AVALIAÇÃO DA AÇÃO EXTENSIONISTA EM UNIVERSIDADES CATÓLICAS E COMUNITÁRIAS
}

\author{
Fabiana Marques Pereira Bartnik* \\ Itamar Mendes Da Silva**
}

Recebido em: 05 de março de 2009

Aprovado em: 28 de abril de 2009

\begin{abstract}
*Mestre em Educação pela PUC-Campinas (SP), Psicóloga. Consultora de Recursos Humanos. Atuou como Analista de Avaliação Institucional na PUC-Campinas e membro de CPA Centro UNISAL. E-mail: fabi. marquesp@gmail.com

**Dr. em Educação pela Pontifícia Universidade Católica de São Paulo. Profo do Programa de Pós-Graduação em Educação da Pontifícia Universidade Católica de Campinas - PUC-Campinas. E-mail: imendess1@ uol.com.br
\end{abstract}

Resumo: O presente artigo tem por objetivo compreender e analisar como as Universidades Católicas e Comunitárias estudadas realizam a avaliação de suas ações extensionistas. Entendemos que a avaliação do compromisso social da Ação Extensionista constitui um avanço na medida em que propicia a valorização e institucionalização da Extensão. Os resultados obtidos mostraram que em sua maioria, a avaliação da Ação Extensionista nestas Instituições é realizada de maneira informal e não concebida como um instrumento pedagógico que deveria avaliar os efeitos concretos dessas ações que se estendem à sociedade. Apesar disso, observa-se uma Extensão transformando-se em prática acadêmica interligada ao ensino e à pesquisa e significadas de aspectos que caracterizam as Instituições enquanto Católica e Comunitária.

Palavras-chave: Avaliação da ação extensionista. Extensão universitária. Universidade católica e comunitária.

\section{EVALUATION OF EXTENSION ACTIVITIES IN CATHOLIC AND COMMUNITARIAN UNIVERSITIES}

Abstract: The purpose of the present article is to understand and analyze how the Catholic and Communitarian Universities perform the evaluation of their extension activities. The authors believe that the evaluation of the social commitment of these activities constitutes an advance since it values and institutionalizes Extension. The results obtained show that, in the majority of the institutions, the evaluation of the extension activities is performed informally and is not conceived as a pedagogical instrument that should evaluate the effects of these actions upon society. Nevertheless, one can observe that the Extension activities are being transformed into an academic practice in connection with education and research, with aspects that characterize the institutions as catholic and communitarian.

Keywords: Evaluation of extension action. Extension university. Catholic and communitarian university.

O propósito deste artigo é compreender e analisar como as Universidade Católicas e Comunitárias estudadas realizam a avaliação de suas Ações Extensionistas.A busca de respostas se fez por meio de análise documental e entrevista semi-estruturada com os Pró-Reitores responsáveis pela Extensão 
em Cinco Universidades Católicas e Comunitárias, localizadas no Interior de São Paulo e Litoral.

Ao longo dos séculos, a universidade sofreu mudanças que deram diferentes sentidos ao seu papel político e social. Esse seu papel enquanto instituição social está atrelado ao poder vigente de cada época, tentando responder às necessidades e às aspirações de seu tempo, transpondo momentos onde estava mais voltada para atender aos interesses específicos de determinados grupos da sociedade e do próprio Estado do que aos interesses da sociedade como um todo.

No Brasil, a universidade nasce e se consolida influenciada por modelos europeus de universidade e pelas ações da Igreja católica. Influenciada pelo modelo jesuítico, nossa educação superior foi organizada segundo um currículo clássico, visando ao treino da mente e à cultura geral. Importante destacar que a universidade surge tardiamente como afirmou Anísio Teixeira (1968) e pelas mãos de um Estado que não se separa da igreja. Embora as primeiras Universidades Brasileiras sejam criadas sob a égide do Estado laico a lógica religiosa permanece a se impor na sociedade como um todo e a influenciar sua organização. É imprescindível afirmar que a criação de Universidades Católicas só acontece a partir da década de 1930, demarcada pelo enfrentamento à iniciativa dos liberais de defender o ensino laico, pois até esta data a igreja se preocupa mais com a formação de seus quadros religiosos.

Também a Extensão Universitária no Brasil data do começo do século XX, mas esta é influenciada por duas correntes: européia, por meio dos cursos de Extensão, resultantes dos esforços autônomo dos intelectuais, com objetivo de aproximar-se da população; e a norte-americana, voltada para o desenvolvimento das comunidades, caracterizada pela prestação de serviços.

Embora o ensino superior tenha sido criado durante a permanência da família real portuguesa no Brasil (1808 a 1821), a primeira organização desse ensino em universidade, por determinação do governo federal, só apareceu em 1920, com a criação da Universidade do Rio de Janeiro, pelo decreto $\mathrm{n}^{0} 14.343$ de 07 de setembro de 1920. Essa criação, não passou da agregação de três escolas superiores existentes: Faculdade de Direito, Faculdade de Medicina e Escola Politécnica.

O Estado segue criando novas universidades pela agregação de faculdades. Na época, o perfil de Universidade é o profissional: "a elite formava-se em escolas superiores que embora visando à cultura profissional davam sobretudo ênfase ao sentido liberal das antigas e nobres profissões de Direito e da Medicina." (TEIXEIRA, 1968, p. 28). A formalização deste perfil se dará em 1931, com 
o decreto 19.851, de 11 de abril, que estabelece o Estatuto das Universidades Brasileiras, e fixa os fins do ensino universitário no seu artigo $1^{\circ}$ :

O ensino universitário tem como finalidade: elevar o nível da cultura geral; estimular a investigação cientifica em quaisquer domínios dos conhecimentos humanos; habilitar ao exercício de atividades que requerem preparo técnico e cientifico superior; concorrer, enfim, pela educação do individuo e da coletividade pela harmonia de objetivos entre professores e estudantes e pelo aproveitamento de todas as atividades universitárias, para a grandeza da Nação e para o aperfeiçoamento da Humanidade. (ROMANELLI, 2002, p. 132)

No período de 1930 a 1954, muitas universidades foram criadas. A Universidade de São Paulo (USP) é fundada em 25 de janeiro de 1934. Durante esse período as Universidades Católicas recém criadas são nomeadas Pontifícias Universidades Católicas, sendo visível a pressão da Igreja no sentido de garantir sua presença e segurança enquanto comunidade católica na defesa dos princípios cristãos para toda a comunidade nacional. Por isso, o interesse da Igreja em fundar Instituições Católicas estrategicamente posicionadas no país, a exemplo das Pontifícias Universidades Católicas: São Paulo/SP, Campinas/ SP, Belo Horizonte/MG, Rio de Janeiro/RJ, Curitiba/PR e Porto Alegre/RS.

Entre os anos de 1955 e 1964 foram criadas mais 21 universidades, sendo 5 Católicas e 16 estaduais. Proporção essa bem razoável para a época, denotando que educação e religião são processos essencialmente políticos pelas ações de poder que executam e sofrem e pelas relações com o poder nas quais se inserem os diversos agentes da sociedade.

A Universidade Católica se desenvolve no Brasil com uma trajetória de pouca tradição em pesquisa, mas com uma característica forte que era de ser uma instituição disponível para o serviço à comunidade/ sociedade e atendimento aos mais necessitados.

O sentido da função social da Universidade Católica desenvolveu-se numa postura coletiva, marcada por uma dinamicidade dentro do universo com o qual interagia, buscando novos conhecimentos e articulada a valores como a ética, justiça, vida e a doação para o outro como temos no documento a seguir:

A Universidade Católica, a par de qualquer outra Universidade, está inserida na sociedade humana. Para a realização do seu serviço à Igreja, ela é solicitada - sempre no âmbito da competência que lhe é própria - a ser instrumento cada vez mais eficaz de progresso cultural quer para os indivíduos quer para a sociedade. (VATICANO, 1990) 
A universidade católica que se forma neste processo nasce inspirada em um duplo referencial que dá sentido à sua identidade: o referencial antropológico e o referencial teológico, na medida em que ambos, também, podem assumir um viés conservador ou um viés transformador. Essa personalidade ambígua pode ser considerada como fator que dificulta a caracterização das universidades confessionais, pelo fato de que elas são sensíveis e vulneráveis aos agentes determinantes da realidade cultural, social e econômica na qual estão inseridas, bem como às influências de políticas e relações de poder intramuros.

Os debates que envolveram a construção da LDB no 4.024 de 1961, apesar da oposição público-privado que o permeou, levaram a lei a estabelecer parâmetros para coexistência entre escola pública e privada.

Durante o período de 1964 a 1990, o Governo busca retomar o crescimento do país dando enfoque a planos que induzem a educação à uma indústria de prestação de serviços e como instrumento para o desenvolvimento econômico (FAGUNDES, 1985). Mas é na década de 1990 que a Universidade vai ganhar contornos mais precisos, a considerar que as políticas educacionais sofrem modificações significativas, e o conjunto dessas ações resulta na aprovação da Lei de Diretrizes e Bases da Educação Nacional - LDB - ou Lei n. ${ }^{\circ} 9.394$, de 20/12/1996. (BRASIL, 1996)

A LDB distingue, em seus artigos 19 e 20, dois tipos de IES segundo sua natureza administrativa - pública ou privada - e lhes garante uma identidade com contornos mais definidos. As IES Católicas e Comunitárias compõem o conjunto das instituições privadas com as seguintes definições:

Art. 20 - As instituições privadas de ensino se enquadrarão nas seguintes categorias: I - particulares em sentido estrito, assim entendidas as que são instituídas e mantidas por uma ou mais pessoas físicas ou jurídicas de direito privado que não apresentem as características abaixo; II -comunitárias, assim entendidas as que são instituídas por grupos de pessoas físicas ou por uma ou mais pessoas jurídicas, inclusive cooperativas de professores e alunos que incluam na sua entidade mantenedora representantes da comunidade; III - confessionais, assim entendidas as que são instituídas por grupos de pessoas físicas ou por uma ou mais pessoas jurídicas que atendem a orientação confessional e ideológica específica e ao disposto no inciso anterior; IV - filantrópicas, na forma da lei. (grifo nosso)

A expressão "universidade comunitária" vem se firmando mais do que "universidade pública não-estatal" ou "universidade confessional", expressões utilizadas em diversos documentos (GADOTTI, 1990, p. 75-85). Este 
autor justifica ainda que, em alguns estudos realizados, essas universidades não devem estar submetidas a nenhum interesse empresarial, e sim devem ter uma profunda vinculação com a região e devem ter uma estrutura democrática de gestão. $\mathrm{O}$ que as distingue das estatais e das particulares não é tanto o seu estatuto jurídico, mas o seu projeto pedagógico, entendido num sentido mais amplo de projeto social e político. Portanto, o que constitui o seu perfil básico é o seu caráter público, social e realmente comunitário.

A universidade que tem em seu seio a missão eminentemente comunitária estará empenhada na construção de uma sociedade mais justa, igualitária e democrática. Essa Universidade Comunitária tem um perfil acadêmico-social, aberto aos estímulos sociais, às carências da sociedade e mais: com função educativa do desenvolvimento e aplicação do conhecimento, para e com a sociedade. São características extremamente valiosas para uma universidade que está na e com a sociedade, mostrando-se com uma identidade que lhe é própria e faz sua ação social na forma de Extensão Universitária.

Pensar e refletir sobre o valor da ação extensionista dentro do compromisso social - não responsabilidade social - das IES (Instituição de Ensino Superior) é imprescindível. Embora existam iniciativas para disseminar o que tem sido feito nas ações extensionistas, a produção nacional sobre o tema, ainda caminha a passos tímidos, restritos às próprias IES, ou seja, pouco compartilhadas com a sociedade.

Na prática da organização e do funcionamento do Ensino Superior Brasileiro, vemos a edificação de um modelo de universidade, com uma filosofia própria, fortalecida. Apesar da existência de um marco jurídico que assegura à Universidade Comunitária, direitos e deveres, a busca de uma definição e caracterização deste modelo se orienta por um conceito muito aberto: a conhecimento de comunidade. O conceito de Universidade Comunitária ganha limites físicos, identidade histórica local e regional e surge de uma população que se organiza e não de uma organização que busca se aproximar de uma população. Nos Estatutos e respectivos Regimento Geral das universidades comunitárias que estudamos, vemos que a identidade de cada uma está presente onde se delineia seu projeto institucional, sua marca política e pedagógica.

É neste contexto que falamos de extensão universitária, pois levando em consideração o processo construído podemos afirmar que existiu ao longo da história toda uma tradição caritativa para com a representação social da Universidade. Trata-se de uma herança profunda e de representativa ação das entidades religiosas no setor. Por força das ações das instituições confessionais, criou-se uma concepção de que o compromisso comunitário está prontamente 
ligado às práticas redistributivas, nas quais a universidade promove ações de redução das desigualdades, captando, via mensalidade, recursos dos segmentos supostamente mais bem favorecidos, revertendo-os à população na forma de prestação de serviços e concessão de bolsas de estudo, seguindo critérios próprios de carência.

Essa relação universidade-sociedade se desenvolveu em termos de uma preocupação mais sistematizada, com o meio social com o qual ela se relaciona na realidade: quando não pelo ensino e pela pesquisa, pela extensão.

Examinar a Extensão universitária no momento atual exige uma revisão da concepção do seu papel enquanto universidade na sociedade. A identidade de uma instituição pode ser definida pelas condutas que a Universidade assume e para que isso se estabeleça é preciso ter um sistema bem articulado de relações entre seus vários componentes.

As Universidades Católicas ainda carregam o sentido de caridade originário na Igreja Católica que resulta em confusão acerca de sua ação. O caráter Católico e Comunitário nas ações das IES carece de uma expressão clara sobre seu objetivo, para não "vender" a extensão Universitária como discurso beneficente e destituí-la de seu significado.

Talvez seja este histórico de extensão como dádiva ou caridade tenha inspirado a crítica de Paulo Freire (1983) acerca do modo com a Extensão era concebida e realizada. Em suas palavras a Extensão assumiu ao longo da história um caráter de imposição cultural, de atitude pouco favorável ao diálogo, indicando a ação de estender alguma coisa a alguém que recebe. Indica que, assim concebido o conceito de Extensão, se relaciona com "transmissão, entrega, doação, messianismo, mecanicismo, invasão cultural, manipulação” (p. 22). Nesta ótica, extensão teria um caráter domesticador, persuasivo, representaria um momento de encontro entre pessoas que julgam saber muito, serem donos do conhecimento - no caso - o extensionista - com pessoas que nada sabem, ou seja, as populações com quem trabalha.

Nesta perspectiva há um equívoco gnosiológico da extensão quando a premissa "estender a" é utilizada, pois se há algo dinâmico na prática sugerida, este se reduz à mera ação de estender, o conteúdo se torna estático - não há mudança, não se dissemina o conhecimento - o sujeito principal no processo de transformação, torna-se um mero depositário de conteúdos.

Para Freire (1983, p. 22), esta visão equivocada da ação extensionista envolve, qualquer que seja o setor em que se realize, a necessidade que sentem aqueles que a fazem, de ir até a "outra parte do mundo", considerada inferior, 
para, à sua maneira, "normalizá-la". Para fazê-la, mais ou menos semelhante a seu mundo.

As análises de Freire levam à ressignificação deste conceito de Extensão impregnado de valores autoritários (funcionalista) incorporando-lhe a noção de comunicação que seria capaz de empreender-lhe outra dinâmica liberta de características ligadas à dominação e à educação bancária.

Acreditamos que a Universidade deve propiciar ao sujeito que dela participa uma dinâmica ativa, em que o conhecimento que emerge do ensino e da pesquisa seja de tal maneira reflexiva, que demande uma presença curiosa do sujeito face ao mundo.

A abertura da universidade para além dos seus próprios muros significa, sem dúvida, a entrada facilitada e desejada dos saberes do povo no seio da vida acadêmica, numa fecunda circulação de acervos comunicantes, todos convergindo para a produção do conhecimento de significação social. (VANNUCCHI, 2004, p. 54)

A visão crítica que nos atemos ao discutir sobre o papel da Extensão nessa relação de sujeito e universidade a partir das contribuições de Paulo Freire (1983) e Vannucchi (2004) propõe uma Extensão que deixa de lado a posição de autoridade, dominadora e depositária de conhecimento, para um encontro com as aspirações do sujeito, que se transforma e é capaz de transformar a Universidade, à medida que esta promove as ações extensionistas.

Extensionismo ou a prática da extensão pode ser então, a forma com que a relação da universidade com a sociedade se manifesta, a partir das atividades que a universidade se propõe a realizar, daquelas que efetivamente e das funções que essas atividades vão ter dentro do sistema social vigente. Não é outra a noção teórica embutida na identidade das Universidades Católicas e Comunitárias. Mas, de qualquer forma é fundamental verificar como e com que possíveis instrumentos se empreendem tal proposta, pois não se está a falar de qualquer ação e sim de uma que expresse a instituição que a faz e seja de qualidade reconhecida socialmente. Então, com objetivo de ajudar neste aperfeiçoamento constante das ações surge a avaliação da extensão.

\section{Avaliação da extensão: um tema em aberto}

Acreditamos que as Universidades Católicas e Comunitárias inspiradas na formação humana do aluno e fortalecidas em sua cultura para um estreitamento na relação com a sociedade, não devem somente atuar, gerir e vivenciar as 
ações extensionistas. É imprescindível desenvolver metodologias para avaliar a ação e interação junto à sociedade.

A avaliação como principal meio de reflexão e aperfeiçoamento de toda atividade humana que se realize, entende-se que - em uma Instituição de Ensino Superior que se destina ao pleno desenvolvimento do educando - a avaliação torna-se necessária em todas as dimensões a ela relacionadas e permite o desenvolvimento de mecanismos que propiciem que o processo se retroalimente.

Partindo da premissa que a educação é um bem público, direito do cidadão e dever do Estado, a produção e difusão do conhecimento tem uma responsabilidade pública e finalidade social. A educação superior é um patrimônio público na medida em que exerce funções de caráter político e ético, "muito mais que uma simples função instrumental de capacitação técnica e treinamento de profissionais para as empresas. Essa função pública é a sua responsabilidade social". (DIAS SOBRINHO, 2005, p. 170)

A partir dessa contribuição do autor, podemos considerar que para a educação superior atender às necessidades sociais, ela precisa se comprometer com a qualidade. No âmbito educacional, o termo "avaliação institucional" só surge em 1934, tendo como referência Ralph Tyler (apud DIAS SOBRINHO; RISTOFF, 2003, p. 18), com estudos na avaliação como instrumento para regulação do conhecimento e as formas de adquiri-lo. Para Tyler, a avaliação tem que averiguar até que ponto os objetivos educacionais traçados estão sendo alcançados pelo currículo e práticas pedagógicas. Surge uma avaliação que diagnostica qualitativamente a rentabilidade e a eficiência da escola, processos pedagógicos e administrativos, mas que também permite um controle do sistema.

Considerando então esse espaço que a avaliação constrói, a educação é um instrumento social, político e econômico que não produz, de forma isolada, a mudança social, mas, nas palavras de Belloni (2000, p. 39), serve de instrumento para que "os sujeitos sociais sejam sujeitos do processo de mudança. O saber científico e o popular, o universal e o regional, são produtos da humanidade e é princípio democrático fundamental que todos tenham pleno acesso a ele”.

Emerge, assim, a função social da avaliação, tal seja a possibilidade de desenvolver uma sistemática que objetive o aperfeiçoamento da qualidade da educação, transformando a universidade que temos hoje, em uma instituição que esteja comprometida com a democratização do conhecimento e da educação para a cidadania. Dentro da perspectiva de avaliação no âmbito educacional e/ ou institucional, avaliar a Universidade é um processo complexo e essencial como instrumento de autoconhecimento e de indicação de caminhos que concretizem sua atuação. 
Por esse entendimento, a avaliação institucional, incorporada à vida universitária, fazendo parte da rotina acadêmica, deve ser um processo contínuo, que busque nortear as políticas institucionais, identificar distorções para corrigi-las e democratizar informações. Deve ser gestada pela instituição e fomentada pelas pró-reitorias ou órgãos similares, envolvendo os departamentos e unidades acadêmicas, em estreita correlação com a missão e o Projeto Pedagógico da instituição e integrada com as demais áreas do fazer acadêmico.

Além do mais para que possa ser analisada, discutida e modificada pela comunidade acadêmica e dessa forma incorporar-se à cultura da instituição, o processo de avaliação da extensão deve iniciar-se, necessariamente, integrado ao processo de avaliação institucional da universidade e deve ter como fundamentos a missão e o perfil da instituição. Esse procedimento orienta a realização de um processo de avaliação que seja de fato institucional, democrático e gerador de mudanças.

Dias Sobrinho (2004, p. 723), considera que

a educação superior deve ser avaliada não simplesmente a partir dos critérios do mundo econômico e não somente com instrumentos que matematizem a qualidade sob as justificativas de desempenho, eficiência e produtividade, mas, sobretudo, deve colocar em julgamento os significados de suas ações e construções com relação as finalidades da sociedade. (grifo nosso)

Dentro dessa perspectiva de compreender o valor e significados das ações que emergem da Universidade, propomo-nos a conhecer como é realizada a avaliação da extensão das Universidades Católicas e Comunitárias.

Caracterizamos aqui Extensão Universitária, como a relação da universidade com a sociedade se manifesta, em vários momentos. Essa relação pode ser vista a partir das atividades que a universidade se propõe a realizar, daquelas que efetivamente realiza e das funções que essas atividades vão ter dentro do sistema social vigente.

Considerando os sujeitos da nossa pesquisa e os objetivos propostos, acreditamos que a avaliação da Extensão é parte integrante de um complexo processo de avaliação institucional, o qual "indica caminhos que orientem a instituição no cumprimento de sua missão social”. (FOREXT, 2002)

A avaliação da Extensão é um dos pontos de grande discussão hoje. Encontros Nacionais, Seminários Regionais e Locais, entre outros, têm buscado tanto nas IES públicas, como nas privadas e comunitárias, debater a legislação e as questões pertinentes à avaliação da Extensão. 
No viés comunitário, a extensão é vista como expressão viva do pensar, do fazer e do agir de professores e alunos, desafiados pela realidade do meio em que vivem, para aprenderem a apreender a sociedade, na investigação da verdade, na busca partilhada de soluções dos problemas coletivos e na construção consciente de uma vida digna para todos. Como indica Vannucchi (2004, p. 55):

Toda autêntica ação extensionista provoca impactos e mudanças, tanto dentro da universidade - à medida que gera novos conhecimentos, repercute em novas opções de pesquisa, influencia na inovação curricular e provoca a real integração de teoria e prática -, como também fora da universidade - pela sua melhor percepção e pelo correto equacionamento dos problemas sociais, econômicos e políticos, próprios do contexto local e regional.

Considerando o objetivo proposto de conhecer a avaliação da Extensão Universitária das Universidades em estudo, a análise do material coletado nos permite empreender discussões bastante relevantes.

A Extensão requer ser avaliada e, por conseguinte, deve ser compromisso da IES levantar, quais procedimentos são adequados para se fazer a avaliação de um objeto tão complexo. O encaminhamento da avaliação demonstra um problema, pois como aponta Dilvo Ristoff (1995, p. 51) não há um modelo pronto e "Creio que é inútil procurá-lo. Ele precisa ser por nós construído".

As universidades pesquisadas majoritariamente não praticam a avaliação na Extensão, mas observamos que todas as IES valorizam a necessidade de desenvolvê-la e consolida-la. Notamos a existência de avaliação para cursos de extensão em forma de questionário e análise qualitativa em duas universidades. Mas no que respeita ao nosso foco de estudo - as ações extensionistas - em seu conjunto, as avaliações são basicamente informais, orais ou, em alguns poucos casos, em forma de relatório final de projeto.

Encontramos a avaliação da extensão, acontecendo da seguinte maneira:

- Observa-se que a Comunidade avalia as ações de extensão, na medida em que solicita a sua presença novamente na comunidade: “[...] tem a comunidade pedindo, ou vindo bater às portas. Avaliamos, muitas vezes, usando as vozes da comunidade" ;

- A avaliação é feita de forma a englobar os resultados obtidos informalmente e consolidar em relatório de reporte de dados para Direção, para Reitoria, demonstrando um pequeno aproveitamento das informações. Não há uma avaliação como ferramenta de "retroalimentação" do processo; 
A gestão Comunitária avalia os projetos informalmente.

A avaliação é oral, nas reuniões, com supervisão, e na atuação do dia-a-dia... Comunidade avalia informalmente a ação da universidade. Alunos avaliam o próprio trabalho e quantificam. Universidade avalia o todo e reporta dados em relatório anual.

Não há nenhum tipo de avaliação sistemática. [...] a forma de avaliar é informal: se o retorno for uma solicitação de fazer a atividade na comunidade novamente, é porque foi bom. [...] Acontece, nos centros, ao final de cada semestre, o Diretor tem seu relatório de atividades e ele avalia como foi sua Extensão. O Relatório é recebido e arquivado.

- Professor avalia alunos envolvidos nos projetos, em forma de relatório técnico. Integradores acadêmicos (responsáveis pelo projeto) elaboram relatório consolidado das ações:

Foi pedido que apresentassem trabalhos técnicos, que apresentassem dados do trabalho desenvolvido, mas não olhamos isso com aquele rigor porque estávamos todos aprendendo a cuidar da extensão numa perspectiva que é que nós acabamos defendendo aí.

Pensando nesta avaliação - sem sistematização e informal - e considerando todo empenho humano, material e acadêmico que a universidade dispõe na realização da ação extensionista, é preciso realizar ações urgentes para que não se percam os valiosos dados do compromisso social da universidade.

A preocupação ainda está no reporte de dados: construir um documento que concretize os resultados das ações realizadas. Não foi possível detectar usos dos dados de avaliação das ações extensionistas, pois como afirma um dos Pró-reitores entrevistados: “O relatório é recebido e arquivado." Na avaliação da fala dos sujeitos observamos que a avaliação até pode existir, mas não se efetiva como uma ação consolidada e socializada junto à comunidade interna ou externa. "Então, não dá pra dizer pra você: "não, eu tenho avaliação", quer dizer, tenho e não tenho [...] Tá lá, tá escrito, mas eu não tenho ainda a leitura dela”.

Sobre possíveis indicadores utilizados, três dos cinco entrevistados, informam que utilizam "categorias" para consolidar os resultados dos projetos. Neste aspecto, é importante afirmar que consolidar resultados é diferente de avaliar os resultados. Esses indicadores são confusos e acabam expressando informações pouco consistentes.

A gente usa categorias para classificar projetos: relevância social, relevância acadêmica... mas é subjetivo... Não. Eu tenho dados, núme- 
ros, mas não indicadores. Tenho um relatório de cada projeto e esses projetos alimentam os relatórios dos programas. E aqui vai ter o número de pessoas atingidas... Mas é complicado. Um projeto era o site das paróquias da cidade: como eu vou dizer que eu atendi 250 mil pessoas?

A avaliação deixa de ser instrumento e passa ser objeto, à medida que a utilizam com foco no reporte de dados para órgãos externos de financiamento, ou apenas para relatórios finais de gestão, como já apontamos.

Acreditando que a avaliação é um processo de emissão de juízos, entendese que o levantamento de dados e a construção de indicadores não esgotam o processo avaliativo, sendo apenas meios científicos e instrumentos de apoio ao processo. Mas não há como utilizar esse recurso, como "quebra-galho". O compromisso com a avaliação deve ser condensado internamente por todas as instâncias que perpassam o próprio Projeto Pedagógico da Instituição (PPI), e na Extensão, o projeto, programa, a demanda social, etc.

A reflexão que propomos é que a avaliação não deve ser apreendida como alvo de controle e fiscalização (quantos atendimentos, relatório de prestação de contas para provar dedicação exclusiva de professor etc.), mas como forma de trazer subsídios que permitam confirmar decisões e ações bem sucedidas, inserir escolhas que se revelem necessárias e reorganizar ações inadequadas. A avaliação não pode ser controladora e também não pode ser simplesmente uma verificação de resultados; não é apenas constatar o que acontece, mas é valorar, é saber o porquê acontece, com foco na melhoria do processo acadêmico. Observamos que a avaliação da extensão não aparece contemplada na política da instituição porque não se tem uma concepção clara do modelo que deveria ser adotado, de que forma fazer, para quem e por quem.

Observamos que para um dos Pró-reitores, a Universidade precisa se organizar internamente para uma dedicação exclusiva à avaliação, no nível de pessoal qualificado: "Investimento de pessoal. Primeiro, porque é difícil a gente conseguir, assim, pessoas pra fazer essa gestão; e pessoas, também, que tenham uma pré-qualificação pra fazer essa gestão."

Um outro afirma que o fazer avaliação não implica necessariamente uma dificuldade, pois o fato de a comunidade dar uma devolutiva via solicitação de novas ações, tende a suprir a necessidade. Questiona também se é necessário sistematizar uma avaliação, pois a dinamicidade da extensão pode ficar comprometida.

[...] a gente poderia criar instrumentos, só que isso me preocupa um pouco em relação à burocracia que teria, e pode perder um pouco 
do foco da extensão. Vocêjá imaginou você tá com uma ação social e, ao mesmo tempo, aplicando questionário, um instrumento, pra saber se [...] se a ação foi boa, se a ação foi ruim? Mesmo de longe passa a parecer uma coisa que eu to fazendo para que ele me diga que eu sou bom, que a Universidade é importante. Mas será que isso é importante?

Acreditamos que a avaliação é ferramenta de gestão, é exercício para execução de qualquer tarefa com qualidade e serve de base para a comparação entre a realidade de um objeto e seu estado desejável. Para os Pró-Reitores, ao não executar uma avaliação, perde-se a oportunidade de comparar as diferentes realidades encontradas na extensão, e deixa-se de fornecer dados, informações, elementos para um planejamento mais satisfatório das atividades extensionistas. "Faz falta, porque o recurso é limitado e quando precisa escolher onde vai ser investido, tem essa preocupação, porque nos reunimos, anualmente, e usamos dados indiretos e não conseguimos colocar isso num único instrumento."

A avaliação tem que ser percebida como um processo que demanda a articulação de diferentes etapas e muitos procedimentos em todas as atividades humanas, como um processo formal e intencional, exigindo a definição prévia de critérios, campos, normas e referências bem explícitas no sentido de guiar a produção de juízos de valor, ou seja, ter como referência os princípios institucionais na análise dos dados e na tomada de decisão a partir dos dados conhecidos. Tudo isso com o propósito de nortear as tomadas de decisão para a transformação da realidade avaliada, sempre visando à melhoria contínua das instituições.

A questão da solidificação de uma Extensão Universitária com clareza em seus propósitos, para o desenvolvimento de uma avaliação, é retomada por um dos entrevistados, como uma angústia:

Está faltando procedimentos, por essa mistura toda do conceito de Extensão. Estamos fazendo um trabalho de mudança de cultura. Explicar para o docente que ação comunitária é uma coisa e extensão é outra [...] estamos tentando mudar a cultura e sistematizar um caminho, mas é difícil.

Parece que há uma grande complexidade e dificuldade para o estabelecimento de indicadores que possam, ao mesmo tempo, ter um caráter geral e também contemplar as especificidades e diversidades próprias da Universidade.

No contexto dos projetos desenvolvidos via Extensão, a avaliação bem elaborada pode ser a expressão nítida do compromisso social da Universidade. 
Agora, se o projeto é pouco claro, seu processo tumultuado e sem objetivos nitidamente definidos, só poderá gerar uma avaliação que o espelhará. Portanto, a opção pelo desenvolvimento de uma avaliação não depende somente da elaboração, aplicação e sistematização de instrumentos, mas acreditamos que depende de todo o contexto de atuação da extensão delineado, com finalidades claras alicerçado na missão da IES, tal como um envolvimento dos sujeitos da ação que tenham o desejo de fazer da avaliação ato político que expresse e divulgue a qualidade, daquilo que a Universidade faz para e com a sociedade.

Encontramos uma carência de critérios e modelos para conduzir sua realização, confusões sobre como fazê-la e, algumas vezes, a própria ausência de uma política de extensão definida que impede o bom desempenho das atividades extensionistas. Nesta perspectiva de discussão, a avaliação é extremamente necessária, pois poderia oferecer elementos para o aperfeiçoamento da própria política de extensão.

Diante à informalidade da avaliação e à inexistência de instrumentos delimitados parece oportuno perguntar: será que a dificuldade identificada de se ter a avaliação incorporada na cultura da instituição localiza-se no campo da avaliação mesmo ou o que se têm explicitado no caso é a fragilidade na própria extensão, que luta por conceituar sua forma expressão de compromisso com a sociedade e de incorporar a identidade institucional nas ações extensionistas? Essas são perguntas que nos fazemos com objetivo de aguçar a discussão ao tema, pois sem avaliação, perdemos a chance de conhecer as potencialidades da ação extensionista.

Acreditamos que a avaliação da extensão pode atuar na totalidade das ações e favorecer a credibilidade do que a extensão produz, no contexto interno e externo. A avaliação serve para legitimar a ação da extensão e pode ser viabilizada de forma a utilizar metodologia quantitativa e qualitativa, cada uma em sua especificidade. No aspecto quantitativo, é necessário sim levantar quantos indivíduos foram atingidos em determinado projeto ou ação extensionista, quantos alunos e docentes envolvidos, etc.; no qualitativo, instrumentos como observação, entrevista e até a utilização da pesquisa-ação, podem focar não só as pessoas que são colocadas em causa, mas as mudanças produzidas pela ação a estas pessoas. De acordo com Dias Sobrinho (1997, p. 83), a avaliação qualitativa "cria condições e situação para o contínuo desenvolvimento e transformação da realidade avaliada e dos indivíduos nela implicados, reconhecendo neles a prerrogativa de serem sujeitos ou atores desses processos em suas relações sociais". 


\section{Considerações finais}

Para que a avaliação funcione, é necessário também a sensibilização desses sujeitos, sobre para que serve e o que se quer com a avaliação. O envolvimento prévio e consciente sobre essa ação pode permitir que a cultura da avaliação seja absorvida e considerando o sujeito como parte do processo, mas sem deixar de lado, que o desenvolvimento de modelo ideal de avaliação está vinculado estritamente às especificidades de cada instituição: da sua concepção de extensão, da sua missão e da sua identidade.

$\mathrm{Na}$ análise que fizemos das Universidades de caráter Católico e Comunitário, observamos que a identidade carrega consigo o comprometimento pela qualidade de ensino, formação ética e humana e a preocupação em agir sem esquecer sua verdadeira missão. A estrutura deste tipo de universidade está na comunidade de pessoas, congregadas pela identidade na fé, na missão, pelos valores morais e religiosos e, em decorrência, organizados para oferecer serviços de educação à sociedade da qual fazem parte.

Não conseguimos ver, em nosso estudo, uma avaliação concebida como um instrumento pedagógico que, ao avaliar o mérito, os efeitos e resultados concretos das ações, possibilita também a identificação das fragilidades. Para que isso aconteça, a avaliação das ações de extensão deve ser inerente à rotina acadêmica da instituição, visto que ela própria objetiva nortear as políticas institucionais, democratizar informações e aprimorar ações.

No âmbito da Legislação Educacional, ainda não há uma Política Nacional que proponha avaliação sistemática da Extensão, como a CAPES (Coordenação de Aperfeiçoamento de Pessoal de Nível Superior) realiza com os cursos de Pós Graduação, ou o INEP (Instituto Nacional de Estudos e Pesquisas Educacionais) com os cursos de Graduação.

Conforme indicamos no início deste texto a avaliação da Extensão Universitária aparece como um tema em aberto, e nossa pesquisa não indicou cenário promissor, ao menos no que respeita às Universidades Católicas e Comunitárias estudadas, e parece necessário pensarmos em formas de atacar a questão. Talvez tenha chegado a hora do MEC, por meio do INEP se preocupar mais com a avaliação da extensão e agir, neste caso, como indutor de políticas, pois a composição do tripé que sustenta e organiza teoricamente a Universidade Brasileira não pode ser "manco". É necessário equilíbrio das ações da universidade para que se possa pensar em qualidade e a avaliação da extensão poderá se constituir numa importante ferramenta neste processo. 


\section{REFERÊNCIAS}

BELLONI, Isaura. A gratificação de estímulo à docência (GED) e a política de educação superior. In: SGUISSARDI, Valdemar (Org.). Educação superior: velhos e novos desafios. São Paulo: Xamã, 2000.

BRASIL. MINISTÉRIO DA EDUCAÇÃO. Secretaria de Educação Superior. Lei 9394. Disponível em: <http://www.mec.gov.br/seed/tvescola/ ftp/eis/lein9394.Doc>. Acesso em: 05 out. 2006.

DIAS SOBRINHO, José. Avaliação quantitativa, avaliação qualitativa. Interações e ênfases. Avaliação Universitária em questão: reformas do Estado e da educação superior. SGUISSARD, Valdemar (Orgs.). Campinas: Autores Associados, 1997.

. Avaliação Ética e Política em função da educação como direito publico ou cidadania. Educ. Soc., Campinas, v. 25, n. 88, p. 703-725, Especial 2004. Disponível em: <http://www.cedes.unicamp.br>. Acesso em: 27 set. 2005.

. Educação superior, globalização e democratização: qual universidade? Revista Brasileira de Educação, São Paulo, n. 28, p. 164-173, jan./abr. 2005. Disponível em: <http://www.scielo.br/scielo. php?script=sci_arttext\&pid=S14134782005000100014\&lng=en\&nrm=iso $>$. Acesso em: 20 Set. 2007.

DIAS SOBRINHO, José; RISTOFF, Dilvo. Avaliação democrática: para uma universidade cidadã. Florianópolis: Insular, 2002.

; RISTOFF, Dilvo. (Org.). Avaliação e compromisso público. Florianópolis: Insular, 2003.

FAGUNDES, José. Universidade e compromisso social: extensão, limites e perspectivas. Tese (Doutorado em Educação). Unicamp, Campinas, 1985.

FÓRUM NACIONAL DE EXTENSÃO E AÇÃO COMUNITÁRIA DAS UNIVERSIDADES E IES COMUNITÁRIAS. Gestão e a avaliação da extensão: um desafio para a comunidade acadêmica. Florianópolis, SC: 2002. Disponível em:< www.ucb.br/extensao-comunitarias/carta_ florianopolis.doc>. Acesso em: 15 set. 2005.FREIRE, Paulo. Comunicação ou extensão? 7. ed. Rio de Janeiro: Paz e Terra, 1983. 
GADOTTI, Moacir. Uma só escola para todos. Petrópolis: Vozes, 1990.

RISTOFF, Dilvo I. Avaliação institucional: pensando princípios. In: BALZAN, Newton Cesar; DIAS SOBRINHO, José (Orgs.). Avaliação institucional: teoria e experiências. São Paulo: Cortez, 1995. p. 37 - 51.

ROMANELLI, Otaiza. História da educação no Brasil. 27. ed. São Paulo: Vozes, 2002.

TEIXEIRA, Anísio. Uma perspectiva de Educação Superior no Brasil.

Revista Brasileira de Estudos Pedagógicos, Rio de Janeiro, v. 50, n. 111, p. 21-82, jul./set. 1968.

VANNUCCHI, Aldo. A Universidade comunitária: o que é, como se faz. São Paulo: Loyola, 2004.

VATICANO. Ex Corde Ecclesiae do Sumo Pontífice João Paulo II Sobre as Universidades Católicas. Constituição Apostólica, de 15 de Agosto de 1990. Disponível em: <http://www.vatican.va/holy_father/john_paul_ii/apost_ constitutions/documents/hf_jp-ii_apc_15081990_ex-corde-ecclesiae_po.html >. Acesso em: 18 jan. 2009. 